\title{
Problems of "Digitalization" of Organizing the Management of Training Specialists in Domestic Universities for the Needs of Domestic Organizations and Ways to Solve Them
}

\author{
Aleksandr Kiselev ${ }^{1,2}$, Marina Ugryumova $^{1}$, Aleksandr Sazonov ${ }^{1}$, and Anna Savicheva ${ }^{1}$ \\ ${ }^{1}$ Yaroslavl State Technical University, 150088 Yaroslavl, Russia \\ ${ }^{2}$ Financial University affiliated to the Government of the Russian Federation, Yaroslav branch, \\ 150003 Yaroslavl, Russia
}

\begin{abstract}
Today, the idea of "digitalization" of many areas of activity is being actively implemented in Russia as a factor in the implementation of modern management technologies: "digitalization" of society, "digitalization" of the economy, "digitalization" of production, "digitalization" of management, etc. This idea was not spared by the "digitalization" of the organization of higher education management and the process of training the specialists in Russian universities for domestic organizations. However, not all "good" theoretical ideas have the same "good" practical implementation, since the practice reveals many problems in this area and expects the science to advise on their solution. This article shows the problems associated with the implementation of the ideas of "digitalization" of the organization of domestic higher education and shows possible ways to overcome them and improve the quality of training students as future professionals for domestic organizations, as well as the effective use of "digitalization" in higher education to increase its efficiency as a result of scientific and technological progress. Moreover, the development of such recommendations was based on the historical and modern domestic experience of organizing higher professional education in Russian universities.
\end{abstract}

\section{Introduction}

Currently, Russian society is talking a lot about the need to implement the digitalization projects: "digital economy", "digital society", etc. As a result, the question arises about the "digitalization" of higher education. So, for example, in Russia, the Federal project "Digital educational environment" was adopted for implementation, the purpose of which is "to create conditions for the introduction of a modern and safe digital educational environment by 2024 , ensuring the formation of the desire for self-development and self-education among the students of educational organizations of all types and levels, by updating the information and communication infrastructure, training, creating a federal digital platform" [1]. But, as the practice of organizing the distance learning for the students in Russian universities has shown, it is hard to believe that such changes will take place in the "fate" of 
Russian universities by 2024. And here there is a lot of debate about what prospects and opportunities appear in connection with the "digitalization" of the organization of higher education and what risks arise in this case. So, for example, D.V. Samotovsky and O.N. Maslennikova rightly note that "modern society is characterized by unprecedented development of technologies for storing, distributing, searching and processing information. These technologies have made information more accessible than ever before. The benefits of information accessibility are clear. The risks are less obvious" [2]. And today the time has come not only to discuss these issues, but to develop a domestic, Russian methodology for organizing such training, using modern management technologies. The article outlines the key problems of "digitalization" of the organization of higher education in order to improve its quality, requiring a scientific approach in their resolution, and the main directions of work in this area to train the experts for domestic organizations in the context of "digitalization" of the society and its activities.

\section{Research methods}

To study the identified problems and determine the directions for improving the organization of management in the field of higher education on the basis of its "digitalization", the method of participatory observation, surveys of the teaching staff and university students, studying the feedback of students and their parents, scientific publications of researchers on the problems of teaching students in a distance format have been used, and also processed the information of the questionnaire survey of the students of the Yaroslavl State Technical University. The research materials on this topic have been repeatedly submitted for discussion at various scientific and practical conferences.

\section{Research results and discussion}

There is no doubt that scientific and technological progress is making its own adjustments to the organization of training for future specialists for various subjects of the Russian economy, directly related to the improvement of modern technologies for managing higher education, based on the principles of "digitalization". Today, it has already become the norm that private offices of teachers and students are actively being operated in universities, corporate e-mail is used in communications between them, etc. At the same time, university teachers have the opportunity to communicate with students on websites, chat with the representatives of employing organizations and parents, etc. As a result, domestic researchers most often consider the advantages of distance learning in the context of "digitalization" of various spheres of the society. So, for example, the Internet today is filled with announcements that you can get "distance learning from anywhere in the world, a state diploma, quick admission to universities in Moscow and Russia", etc. [3]. At the same time, Russian researchers singled out its convenience as the main advantage of distance learning, that is, freedom and economy of time and actions, as well as the ability to combine study and work. In addition, "looking back" on foreign experience, domestic researchers often believe that since such a form as "e-education" has been used in Europe for a long time, it means that it will bring the desired results in Russia. And it is precisely the "digitalization" of the organization of higher education management that will allow, through the use of modern information technologies, to improve the quality of Russian higher education and the training of professionals for domestic organizations.

However, something happened that no one expected - the coronavirus pandemic. And the experience of the forced organization of the distance learning for students in Russian universities in the spring of 2020 showed that not everything is so obviously good in this 
area. For example, D. Melnik, the head of the research group at the Center for Education Transformation at the Skolkovo Moscow School of Management, notes that "in general, Russian universities were not ready for the transition to the distance learning, and in the world, most universities act more intuitively in this situation" [ 4]. In other words, universities were not ready for the "digitalization" of student education in the new environment. In addition, the organization of Russian higher education according to foreign templates according to the "bachelor-master" system without adaptation to national traditions and mentality of people shows that the rejection of one's historical experience in the field of higher education organization had a negative impact on the quality of training of the graduates of domestic universities, and the system itself does not take root the way we would like. This is evidenced by the constant "improvement" of the Federal State Educational Standards of Higher Education (FSES HE) [5]. And, unfortunately, the "digitalization" of this system of training modern professionals in Russian universities in its current form without introducing domestic experience and training traditions into it will be doomed to failure. For example, S. A. Syrbu, T. V. Karaseva and A. M. Loshchakov note that "despite a sufficient number of foreign and domestic studies in the field of electronic education, not enough attention has been paid to modern educational policy in Russia. Modern foreign models of e-education cannot be used without adaptation to Russian conditions "[6]. Today, a reflection on the experience of organizing higher education during the coronavirus pandemic in the spring of 2020 is under way. Thus, the results of a survey of more than 35 thousand students from more than 400 universities through online surveys conducted by the experts from the Higher School of Economics together with the representatives of Tomsk State University, showed that by the beginning of summer 2020, the percentage of students who faced certain difficulties with online learning - from $75 \%$ in the spring to $86 \%$ by June 1 . Researchers associate a more critical attitude towards distance learning with fatigue from the online learning format. At the same time, $65 \%$ of students noted that distance learning has become less effective and interesting. They also considered the lack of "live" communication with teachers and fellow students, as well as the difficulty of learning at home using information technologies [7].

In addition, in the course of the surveys, many students noted that when working at home, they spent a lot of time using the Internet, and not always purposefully for their studies. But back in 2008, the journal "Aiianuc" published a resonant essay by the professor of the University of California N. Kara about "whether Google makes us stupid." Based on personal experience and the experience of his colleagues, he expressed his opinion about the destructive effect of the Internet on attention and thinking. And in 2009, the famous American psychiatrist G. Small in his book "Brain Online. Man in the Internet Age" cited data from numerous studies showing the negative impact of the Internet on the cognitive functions of people [8]. For our practice, a situation when a schoolchild or student, having watched the "shooters" games, begins to show aggression not only against his fellow students, but also against the teachers it is no longer something supernatural [9]. At the same time, today it has become a reality that students have stopped reading books, and most often, without special analysis, they take information from the Internet, which is not always scientifically grounded. As a result, they may have a subjective opinion on the issues under study. And here it is very important "live communication" between the teacher and the student, since only in the classroom, with personal contact, the teacher sees the reaction of the students to the information received from him and can react in a timely manner, explaining the material that the students did not understand, which is very important for the future expert.

This is also explained by the fact that the role of knowledge-based activities is increasing in modern conditions. So, for example, with the presence of a large number of modern medical equipment, not a single person would want to get treatment from a doctor 
who received an education on the Internet or fly an airplane with a pilot who was trained to operate it only on the Internet. We can confidently assume that there are no specialties that could be mastered only through modern "digital technologies". And modern students themselves are already aware of this, speaking about the problems in obtaining the professional skills by methods of distance "learning" [10]. So do the universities in difficult conditions: they still prefer a full-time and part-time mode of study, so that laboratory and practical classes can be carried out using the necessary material base, which cannot be done in a distance format. Otherwise, it is difficult to speak about the effective formation of the trainees' professional competencies. An example of this is the experience of organizing training for students of technical specialties in a part-time format at Yaroslavl State Technical University.

This begs the question: what does "civilization" mean in training the professionals for domestic organizations? From the pedagogical point of view, "digitalization" of the organization of higher education should be understood not as a remote mode of teaching students, not organizing online learning, but a whole range of activities that require their implementation using all modern technologies, including, and perhaps mainly the information technology. We live in the 21 st century today. But do domestic universities today, especially regional ones, have the opportunity to provide their teachers and students with modern "digital" means? So, for example, the departments usually have several computers for the work of teachers and, as a rule, are already quite old, given that the life cycle of modern computer technology is 3-6 months. The workplaces of teachers of the universities in their equipment do not meet the requirements of modern practice of "digitalization" of the organization of student education in the universities [11]. The organization of the teacher's workplace is his problem. But having bought, for example, a laptop, the teacher himself installs software, which may not be compatible with the devices that students have. And many students generally use their iPhones as a universal tool for telecommuting. So, for example, when leaving for a distance learning in the fall of 2020, when organizing training in one of the universities in Yaroslavl, two sets of mini video cameras and sound speakers were purchased for each department to organize the training of students. In addition, many state universities, especially regional ones, do not have the opportunity to possess a modern material base to ensure the quality of student education using the information technologies. Even in the classrooms, the main component for teaching students is an ordinary blackboard and chalk. And an interactive blackboard in each classroom of the university is still a dream of the teachers, who in practice often have only a superficial understanding of how it can be used in practice in educational work. In this case, it is difficult to say that each student has an equipped workplace in the classroom with the ability to use modern information technologies when working in the classroom. And the inability to use modern teaching aids and use modern information technologies in teaching leads to the problems in the transition to a distance learning format, and in general, to a decrease in the quality of professional training of students and an increase in stress in the activities of both teachers and students. For example, L.V. Rebysheva and E.V. Vasilchenko note that an expert survey in February 2014 at Tyumen Oil and Gas University made it possible to identify the advantages and disadvantages of distance learning in comparison with traditional forms of education (full-time, part-time) in higher education and also to identify the main factors influencing the effectiveness of distance education. They found that "one of the reasons for the low level of implementation of distance learning technologies in the educational process at the university is that the formation of the material and technical base for distance learning began with a certain lag and university leaders only recently realized the importance of distance learning. In addition, this is the high cost of development, implementation, support of electronic distance learning systems, lack of the necessary technical support, a small number of qualified teachers for the 
implementation of distance learning, an insufficient number of full-fledged electronic courses in the universities" [12]. And practice has shown that in 2020 the situation in domestic universities in this area has practically not changed. E.R. Orlova and E.I. Koshkina highlight the following "problems inherent in the current state of distance technologies in the educational sphere of Russia": "problems of introducing distance technologies; quality of distance learning; financing; informing Russian students about the availability of high-quality distance courses; methods for the effective implementation of distance learning; organization of distance learning systems; lack of training systems for teachers in the use of modern ICT" [13]. As a result, as the students and their parents note in the course of the surveys, teachers often "lack understanding of online teaching methods and skills for remote knowledge transfer, and therefore distance learning turns into a system of self-education" [14]. At the same time, today many teachers, according to trainees' assessments, "simply post their homework on social networks, for example, learn a paragraph of a textbook informally and outline it. To master the material for real, trainees have to take additional lessons on specialized online sites" [9]. Therefore, according to D.O. Rogozin, today "much more widespread fears of the remote format, which suddenly became the only one and with no alternative. Everyone understands that such a transition is temporary - it is associated with an emergency situation, the threat of infection. But how the higher education will develop, how digital formats will enter the life of students and teachers, where the border between coercion and choice will pass - the questions are open" [15].

This question should be addressed not only to the teachers, but also to higher education authorities. Today it is stated that, for example, it is planned to provide for $100 \%$ of students in $100 \%$ of educational organizations implementing basic general education programs by 2025, an equal opportunity to receive education in conditions corresponding to the target model of the "Digital School" with the possibility of implementing a personal educational trajectory, taking into account individual psychological characteristics [16]. However, as we can see, the situation with the "digitalization" of higher education organizations experienced the same problems in 2020 that had already been in 2014. In addition, the division of the Ministry of Education and Science of the Russian Federation into two ministries: the Ministry of Education and the Ministry of Science and Higher Education has led to the fact that the organization of school education is progressing at a faster pace in terms of equipping educational institutions with modern "digital" technologies and modern "digital" equipment. As a result, it is difficult to believe that fundamental changes will take place in the "digitalization" of the organization of higher education. Both trainees, teachers, and leaders of educational organizations perceive the transition to distance learning as a forced and temporary measure and are waiting for when it will be possible to return to the usual learning.

However, it should be noted that, firstly, the "digitalization" of the organization of higher education is not the organization of distance learning. It should be understood that traditional teaching ("live" contact between students and teachers) in modern conditions is unthinkable without the use of modern technology. But this does not replace the teacher's activity in direct communication with the students. Previously, the teacher drew, for example, some kind of diagram for the students on the blackboard. Today, the teacher can make the slides that will naturally be more informative and of high quality and beautifully designed. Undoubtedly, this makes it easier for the learners to perceive the material in this form. And the teacher, taking into account the time of the lesson, can show several slides that he needs to work with the students, while when drawing them on the blackboard, he would not have enough time for the lesson. Naturally, in the presence of an interactive whiteboard, the learning process will be more visual and will expand the possibilities of teachers in explaining the educational material to the students. And "digitalization" in the 
field of higher education should allow the teachers to use modern digital technology and equipment at the university that they need to improve the quality of education, including for the formation of the professional competencies they need to work in domestic organizations. As a result, it is necessary to perceive the "digitalization" of the organization of student education in domestic universities not as a "headache" for the teacher, but the opportunity provided by the university to use the most modern digital technologies in teaching the students regardless of the format of the training - full-time, part-time or distance.

Secondly, given the fact that information technology is undergoing rapid changes, the teacher must be able to apply them while teaching his students. However, today this also remains a matter for the teacher himself: whether he wants to do it or not. Organized training of the teachers on this issue in universities, as a rule, is not provided, and such a requirement is not imposed on teachers. As a result, the teacher often lags behind students in the ability to use modern information technologies, who master them faster both in school and in everyday life. It is also necessary to take into account the fact that many teachers in universities are of considerable age, as a result of which they have already "lagged behind" those information technologies that are used in real production or will be used in the near future. In addition, many teachers have practical experience in organizations, but do not have professional pedagogical training, which does not allow them to effectively use modern pedagogical methods to implement an individual learning trajectory in the context of "digitalization" of student learning organization. So, for example, Doctor of Pedagogical Sciences, Professor L.V. Baiborodova, reasonably asserts that "experience convinces us that the choice of technologies for further use in practical activities depends on the skill of the carrier of information about the technology, because of how this or that technology has been presented" [17]. And this problem is also far from being resolved. But in combination, all these problems do not allow using the possibilities of "digitalization" to improve the quality of training students in domestic universities as modern professionals for domestic organizations.

\section{Conclusion}

Today, the problems that need to be solved in universities from the standpoint of implementing the concept of "digitalization" in training the professional personnel for domestic universities have become clear. Unfortunately, many programs of "digitalization" of higher education organizations being adopted today "force" state universities to "paint" a beautiful picture of the implementation of this concept in their activities. However, practice shows that many universities, primarily regional ones, have an outdated material and technical base, since there is no funding for its improvement at the required pace. And universities are trying to at least somehow meet the call of the times for their development, they are looking for sponsors from among regional organizations for the implementation of individual projects that are possible in specific conditions. But without clear criteria for work in the designated area and appropriate funding from the state for the implementation of the concept of "digitalization" in universities, no "improvement" of the Federal State Educational Standard of Higher Education will enhance the quality of professional training of a future expert who is able to use the best innovations and digital technologies in his work. It is like teaching a person to swim without having a pool or a pond. He will know the ropes of the theory, but he will never float, since he himself did not try to do it during training. Thus, the time has come to address the issues of implementing the concept of "digitalization" of the organization of students in Russian universities from the state interests, from the interests of the domestic economy. Otherwise, there will shortly be no experts in Russia capable of not only creating, but also using the proposed foreign "digital" 
technologies in their practical work in organizations, since the universities will not give them such a practice. And this problem needs to be solved urgently, since we are already lagging behind the developed countries of Europe and China in the issue of training the professionals for high-tech production.

The modern Russian higher school has a fundamental scientific base that makes it possible to prepare a comprehensively developed graduate, but the onset of the information era and globalization in education require its modernization, the use of new approaches to organizing the activities of higher education. This necessitates the modernization of higher educational institutions, the development of innovative areas of study that combine flexibility, scalability, convenience of obtaining knowledge, accessibility for the student, based on modern information technologies that can satisfy the needs of students in obtaining relevant information for professional and personal growth, which, ultimately, it is an objectively necessary condition for the entry of Russian higher education into the world educational space [12].

Thus, it should be noted that the "digitalization" of the organization of student training should equally use both full-time and distance learning formats for students. And this is neither a tribute to fashion, nor a commercial project, but the need in modern conditions to prepare the professionals necessary for domestic organizations, capable of providing them with the required level of competitiveness and the timely introduction of innovations into the production activities. And the organization of student training in such conditions should not become a problem for the university teachers. Probably, today is the time when the necessary material and technical background should be created in the universities, including the provision of teachers and students with the equipment they need, the necessary methodological support for teaching the students and the systematic and planned preparation of teachers and students to work using the most modern digital technologies.

\section{References}

1. Federal project "Digital educational environment", https://futurerussia.gov.ru/

2. D.V. Samotovinsky, O.N. Maslennikova, Russian University in an unstable world: global challenges and national responses: materials of the national scientific and practical conference, February 5-8, 2, 192 (2019)

3. E-education in Russia, https://online-institut.ru/

4. D. Melnik, Quarantine as a reason to reconsider the approach to higher education, https://tass.ru/

5. A. A. Kiselev, Trends in the development of education: teacher, educational organization, society - 2020: materials of the All-Russian scientific and practical conference, September 28, Cheboksary, 64 (2020)

6. S.A. Syrbu, T. V. Karaseva, A. M. Loshchakov, Russian University in an unstable world: global challenges and national responses: materials of the national scientific and practical conference, Ivanovo, February 5-8, 2, Ivanovo, 203 (2019)

7. Students named the main problems of online learning, https://www.rbc.ru/

8. G. Small, G. Vorgan, Brain online, People in the Internet era, 352 (2011)

9. A. A. Kiselev, Development of education, 2(8), 97 (2020)

10. 10 problems of distance learning and ways to solve them, https://zaochnik.ru/

11. A. A. Kiselev, Electronic scientific j., 1(30), 41 (2020)

12. L. V. Rebysheva, E. V. Vasilchenko, Modern problems of science and education, 2-2, http://science-education.ru/ 
13. E. R. Orlova, E. I. Koshkina, Problems of distance learning in Russia, https://cyberleninka.ru/

14. Experts have identified the main problems of distance education in the Russian Federation, https://sn.ria.ru/

15. D.O. Rogozin, Threats and opportunities of distance education: a survey of University teachers, https://trv-science.ru/

16. M.Yu. Mikhaylina, E. P. Fedotova, Digitalization of education: experience, problems and risks of distance learning: Methodological recommendations, https://soiro.ru/

17. L. V. Baiborodova, Pedagogical technologies: research results of the Yaroslavl scientific school: monograph, 74 (2015) 